\title{
LIQUID CRYSTALLINE PROPERTIES OF HYDROXYPROPYL CELLULOSE PREPARED FROM DISSOLVED EGYPTIAN BAGASSE PULP
}

\author{
RAGAB E. ABOU-ZEID, ${ }^{*, * *}$ NAHLA A. EL-WAKIL, ${ }^{*}$ AHMED ELGENDY, \\ YEHIA FAHMY* and ALAIN DUFRESNE** \\ *Cellulose and Paper Department, National Research Centre, 33 Bohouth Str., \\ Dokki, Giza 12622, Egypt \\ ** Université Grenoble Alpes, CNRS, Grenoble INP, LGP2, F-38000 Grenoble, France \\ Corresponding author: Ahmed Elgendy, drelgendy2000@yahoo.com
}

Received June 26, 2020

Egyptian agricultural wastes were used for preparing advanced cellulosic derivatives possessing liquid crystalline properties. Cellulose was successfully isolated in pure form from Egyptian bagasse pulp. Hydroxypropylation was carried out on the obtained cellulose and the liquid crystalline properties were investigated. The prepared hydroxypropyl cellulose (HPC) was esterified with 4-alkyloxybenzoic acids, giving products with liquid crystalline properties. The molecular structure of HPC and a series of its esters - 4-alkoxybenzoloxypropyl cellulose (ABPC- $m$ ) was confirmed by Fourier transform infrared (FT-IR) and ${ }^{1} \mathrm{H}$ NMR spectroscopy. The liquid crystalline (LC) phases and transition behaviors were investigated using differential scanning calorimetry (DSC) and polarized light microscopy (PLM). The lyotropic behavior in dimethyl acetamide (DMA) was investigated using an Abee refractometer, and the critical concentration was determined by measuring the refractive index of the solutions in DMA.

Keywords: cellulose, bagasse pulp, 4-alkyloxybenzoic acids, liquid crystalline properties, phase transitions

\section{INTRODUCTION}

Cellulose, the most abundant natural polymer, could be a primary chemical resource in the future, as it is renewable, biodegradable, biocompatible, and derivatizable. ${ }^{1}$ However, cellulose has not yet reached its potential applications in many areas, because it is difficult to process in normal solutions or in the melting state on account of its strong intermolecular and intramolecular hydrogen bonding system.

The extraction of cellulose from biomass involves the removal of lignin, hemicelluloses and pectins. A lot of methods have been suggested and used by different researchers to extract cellulose from different plants. ${ }^{2-4}$ The methods generally involve basic or oxidative treatments that have the ability to discharge cellulose.

One of the largest cellulosic agro-industrial by-products is sugarcane bagasse. In recent years, there has been an increasing trend towards the utilization of agro-industrial residues, including sugarcane bagasse. Bagasse can be used for energy production or for non-energy applications, and currently, there is much research on the uses of bagasse in the synthesis of cellulose derivatives, as it possesses about 40 to $55 \%$ cellulose..$^{5-6}$ Cellulose acetate was successfully prepared from cellulose extracted from bagasse. Other studies related to the preparation of methylcellulose $\mathrm{e}^{8-9}$ and carboxymethylcellulose $\mathrm{e}^{10-11}$ from bagasse have been reported.

Liquid crystals are anisotropic fluids of supramolecular assemblages that exist as intermediate phases of condensed matters between isotropic fluid and solid-state crystalline phases. ${ }^{12}$ One of the most important cellulose derivatives is hydroxypropyl cellulose (HPC), which is extensively used in several activities. Hydroxypropyl cellulose (HPC) derivatives are 
known to exhibit thermotropic liquid crystal phase with unique optical properties. ${ }^{13}$

In the past 20 years, the interest has been focused on the study of the liquid-crystalline characteristics of cellulose and its derivatives since Werbowyj and Gray ${ }^{14}$ found a cholesteric liquid-crystalline phase in concentrated aqueous solutions of HPC. HPC itself, ${ }^{15} \mathrm{HPC}$ derivatives ${ }^{16}$ and other fully substituted cellulose derivatives ${ }^{17}$ ${ }^{18}$ with flexible side chains have been reported to melt readily, forming thermotropic liquid crystalline mesophases. HPC is able to form both lyotropic and thermotropic mesophases. ${ }^{15,20-21}$

In a previous work, ${ }^{22}$ derivatization of fully substituted HPC with alkoxybenzoic acid derivatives, bearing $1,2,3,4,7,8,10,12$ and 14 carbon atoms in the alkoxy chain, was performed and the liquid crystalline properties of the derivatives were studied. The study showed the dependence of liquid crystalline properties (lyotropic and thermotropic) on the alkoxy chain length. In the present work, HPC was synthesized from dissolved bagasse pulp and modified with several benzoic acid derivatives bearing terminal alkoxy chains, via the esterification reaction, to elucidate the relationship between the side chains and the mesophase behavior of the resulting esters. Moreover, the effects of the degree of substitution of HPC on the extent of derivatization and on the liquid crystalline properties were studied.

\section{EXPERIMENTAL}

\section{Raw materials}

Bleached bagasse pulp was supplied from Qena Company, Egypt. The cellulose and hemicellulose contents of the pulp were $67.7 \%$ and $30 \%$, respectively. The constituents of the prepared dissolved pulp and DP were characterized, and were as follows: $\alpha$-cellulose (94\%), lignin (0.8\%), hemicelluloses (about 3\%), ash (1.1\%) and DPv (550). Other chemicals $(\mathrm{NaOH}$, methyl alcohol, isopropyl alcohol, potassium hydroxide, propylene oxide, hydrochloric acid and sulfuric acid) were of laboratory grade. Para-p-toluenesulfonyl chloride ( $\mathrm{TsCl}$ ), anhydrous pyridine, dimethyl acetamide (DMA), 4alkoxybenzoic acid $\left(\mathrm{C}_{\mathrm{m}} \mathrm{H}_{2 \mathrm{~m}+1} \mathrm{OC}_{6} \mathrm{H}_{4} \mathrm{CO}_{2} \mathrm{H}, \mathrm{m}=2,10\right.$ and 12) were all purchased from Aldrich and used as received.

\section{Preparation of dissolved bagasse pulp}

Hydrolysis of the bleached pulp was performed by adding $25 \mathrm{~mL}$ of $2 \mathrm{M} \mathrm{HCl}$ per gram pulp in an Erlenmeyer flask. The solution was refluxed for 20 min and washed with distilled water until the acidtreated sample was neutralized to $\mathrm{pH} 7$.
Hemicelluloses were degraded from pulp by extraction with $10 \% \mathrm{KOH}$ (liquor ratio of 20:1) at room temperature for $20 \mathrm{~h}$, with stirring followed by washing with distilled water until neutrality. ${ }^{23}$ The extraction was repeated twice. The degree of polymerization of the bagasse pulp and the dissolved bagasse pulp was determined by measuring the intrinsic viscosity $[\eta]\left(\mathrm{cm}^{3} \cdot \mathrm{g}^{-1}\right)$, using the NFT 12-005 method.

The average degree of polymerization (DPv) of both pulps was obtained using the law of MarkHouwink (Eq. 1):

$[\eta]=K\left(\overline{D P_{v}}\right)^{\alpha}$

\section{Hydroxypropylation of dissolved pulp ( $\left.\mathrm{HPC}_{\mathrm{B}}\right)$}

The reaction was carried out in two steps: alkalization and etherification of cellulose under heterogeneous conditions. Aqueous $\mathrm{NaOH}(22 \% \mathrm{w} / \mathrm{v})$ was added to finely pulverized cellulose $(1.0 \mathrm{~g})$ in isopropanol $(10 \mathrm{~mL})$ at ambient temperature, with continuous stirring for $1 \mathrm{~h}$ in a closed vessel. Alkali cellulose was squeezed to remove the excess alkali and to reach the weight gain of $150 \%$, then it was transferred to a three-necked round-bottom flask of $250 \mathrm{~mL}$ capacity, fitted with a coiled condenser and nitrogen inlet. Ice-cold water was circulated in the condenser throughout the reaction. Propylene oxide $(17 \mathrm{~mol})$ and isopropanol $(50 \mathrm{~mL})$ were added and the reaction was allowed to proceed at $60{ }^{\circ} \mathrm{C}$ for $6 \mathrm{~h}$. After neutralizing the excess alkali with acetic acid, the synthesized hydroxypropyl cellulose $\left(\mathrm{HPC}_{\mathrm{B}}\right)$ sample was dissolved in water, precipitated in acetone, filtered, and washed with acetone. The purification was repeated three times and the obtained product was dried at $60{ }^{\circ} \mathrm{C}$ in an oven.

\section{Preparation of ABPC- $m$ from HPC prepared from dissolved pulp}

An amount of $2.0 \mathrm{~g}$ of the synthesized hydroxypropyl cellulose $\left(\mathrm{HPC}_{\mathrm{B}}\right)$ corresponding to $16.14 \mathrm{mmol}$ based on the hydroxypropyl unit was stirred in DMA $(20 \mathrm{~g} / \mathrm{L}) .6$ molar equivalents of 4alkoxybenzoic acid $(2,10$ and 12 carbon atoms in the side chain) were added, as well as pyridine and $\mathrm{TsCl}$, and stirred for at least $24 \mathrm{~h}$ at $80{ }^{\circ} \mathrm{C}$. The reaction mixture was then poured into cold methanol. ABPC- $m$ was separated as a white sticky mass. For purification, the filtered precipitate was dissolved in acetone, and then reprecipitated with cold methanol to get rid of all unreacted acid and other byproducts. The derivatives were purified at least four times by dissolution and reprecipitation, and finally, the product was dried under vacuum at $60{ }^{\circ} \mathrm{C}$.

\section{Calculation of the degree of substitution of HPC} using ${ }^{1}$ HNMR

For all mathematical formulas set out below, the following abbreviations have been adopted: DSHPC $=$ 
degree of substitution of hydroxypropyl groups per anhydroglucose unit of cellulose; $\mathrm{I}_{\mathrm{CH} 3}=$ integration corresponding to the terminal protons of HPC; $\mathrm{I}_{\mathrm{g}}=$ integration corresponding to protons of carbohydrate units of cellulose ether.

The degree of substitution of HPC is defined as the number of grafted hydroxypropyl groups per anhydroglucose units of cellulose (Eq. 2):

$$
\text { DSHPC }=\frac{\text { number of chains }}{\text { number of anhydroglucose units }}
$$

The number of chains of hydroxypropyl groups is equal to the integration of hydrogen corresponding to terminal protons of the HPC $\left(\mathrm{CH}_{3}\right.$ terminal $)$ divided by 3, as written in Equation 3:

Number of chains $=\frac{\mathrm{ICH}_{3}}{3}$

The number of sugar units is equal to the integration of the sugar protons divided by the number of hydrogens that are not substituted by the hydroxypropyl chain. There are 10 hydrogen carbohydrate units, as given in Equation 4:

Number of anhydroglucose units $=\frac{\mathrm{Ig}}{10-\mathrm{DSHPC}}$

From Equations 2, 3 and 4, it follows:

$D_{\text {SHPC }}=\frac{\mathrm{ICH}_{3}\left(10-\mathrm{D}_{\text {SHPC }}\right)}{3 \mathrm{Ig}_{\mathrm{g}}}$

From Equation 5, it follows:

$D_{\text {SHPC }}=\frac{10 I_{\mathrm{CH} 3}}{3 I_{\mathrm{g}}+\mathrm{I}_{\mathrm{CH} 3}}$

Calculation of the degree of substitution of ABPC$m$ using ${ }^{1}$ HNMR

The DS of ABPC- $m$ is then obtained by the ratio of integrations of methyl protons of terminal chains and carbohydrate protons by applying the formula of Equation 7:

$\mathrm{DS}=\frac{28 \mathrm{I}_{\mathrm{CH} 3}}{3 \mathrm{I}_{\mathrm{g}}+\mathrm{I}_{\mathrm{CH} 3}}$

\section{Physical characterization}

IR spectra were measured on a JASCO 300-E Fourier transform infrared (FTIR) spectrometer. The spectra were obtained by preparing dried $\mathrm{KBr}$ powder pellets containing $1 \% \mathrm{w} / \mathrm{w}$ of the investigated samples.

${ }^{1} \mathrm{H} \quad \mathrm{NMR}$ spectra were recorded in dimethylsulfoxide (DMSO), using tetramethylsilane (TMS) as reference, on a Varian UNITY400 spectrometer, with a $5 \mathrm{~mm}$ ID-PFG (inverse detection - pulse field gradient) probe. The DS of ABPC- $m$ was determined by $1 \mathrm{H}$ NMR spectroscopy.

Differential scanning calorimetry (DSC Q100 TA Instruments, USA) measurements were carried out for samples (around $8 \mathrm{mg}$ ) placed in a sealed aluminum pan. All thermograms were obtained at a heating rate of $5{ }^{\circ} \mathrm{C} \mathrm{min}{ }^{-1}$ in an inert atmosphere of nitrogen.

Transition temperatures were checked, and the types of mesophases were identified, for the samples investigated with a THMS600 polarized-light microscope (PLM), equipped with a hot stage. To investigate the lyotropic properties, the samples were kept in the dimethylacetamide (DMA) solvent (40, 50 and $60 \mathrm{wt} \%$ ), for at least one week before measurements. Refractive indices were performed on an Abbe 60 refractometer attached to an ultrathermostat, and recorded at $25^{\circ} \mathrm{C}$.

\section{RESULTS AND DISCUSSION}

Hydroxypropylation of dissolving bagasse pulp

Heterogeneous etherification of dissolving bagasse pulp with propylene oxide was performed. HPC with a DS of 1.87 was obtained. An illustrative scheme of this reaction is presented in Scheme 1.

\section{FT-IR spectroscopic analysis}

The FTIR spectra of the dissolved bagasse pulp (cellulose) and the prepared HPC are shown in Figure 1. The spectra exhibit the typical absorption bands of the cellulose backbone $(\mathrm{vOH}$ at $3390 \mathrm{~cm}^{-1}, \mathrm{vCH}$ at $2892 \mathrm{~cm}^{-1}$ and $1420 \mathrm{~cm}^{-1}$, and $\mathrm{VOC}$ at $1070 \mathrm{~cm}^{-1}{ }^{24}$

HPCB showed double absorption bands between 3000 and $2800 \mathrm{~cm}^{-1}$ corresponding to the $-\mathrm{CH}$ stretching vibration of the methylene groups of cellulose and the $-\mathrm{CH}$ stretching vibration of the methyl group of $\mathrm{HPC}_{\mathrm{B}}$, furnishing thereby evidence of hydroxypropylation.

\section{${ }^{1} \mathrm{H}$ NMR analysis}

Figure 2 shows a typical ${ }^{1} \mathrm{H}$ NMR spectrum for a $\mathrm{HPC}_{\mathrm{B}}$ sample (prepared from dissolved bagasse pulp): the strong peak at $1.0 \mathrm{ppm}$ is assigned to methyl protons, whereas the broad peak from 2.8 to $4.7 \mathrm{ppm}$ is attributed to the cyclic glucose units. ${ }^{1} \mathrm{H}$ NMR spectroscopy was employed for determining the DS of the HPC sample. The DS value was calculated and it was found to be 1.87 . 
RAGAB E. ABOU-ZEID et al.
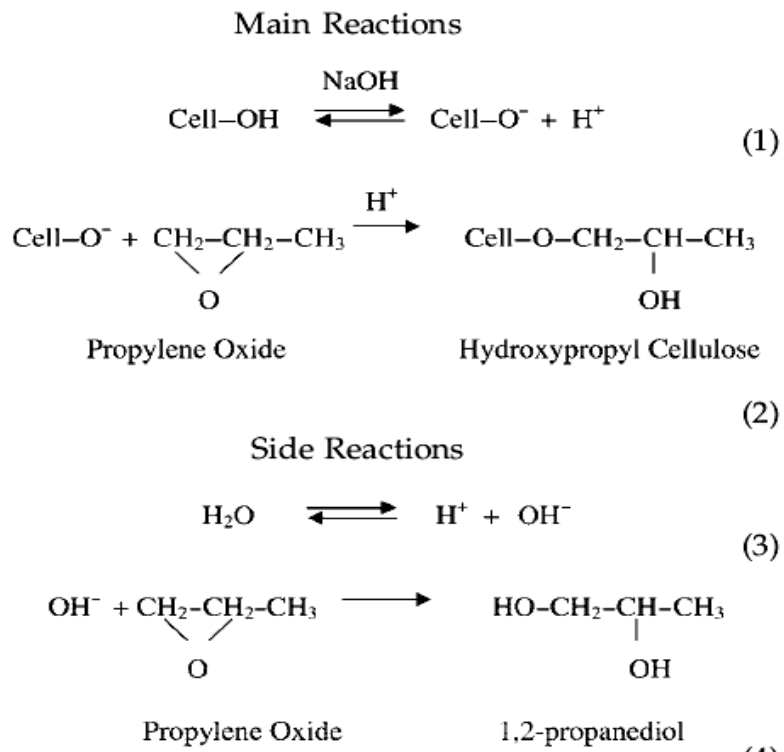

(2)

Scheme 1: Hydroxypropylation of cellulose and the side reactions

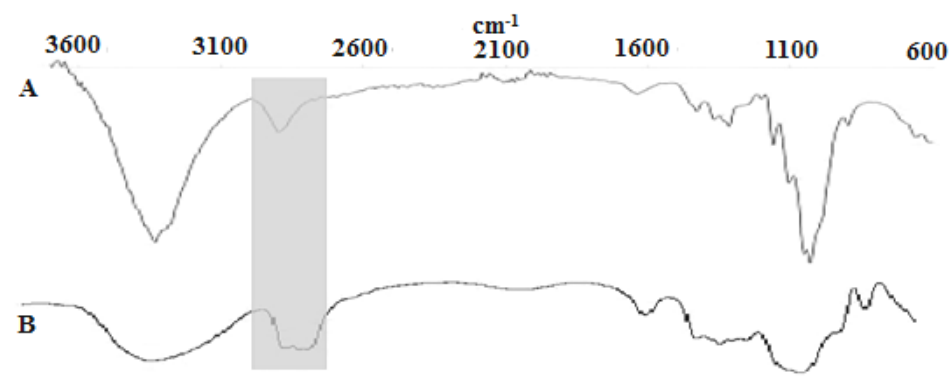

Figure 1: FTIR spectra for (A) cellulose, and (B) hydroxypropyl cellulose

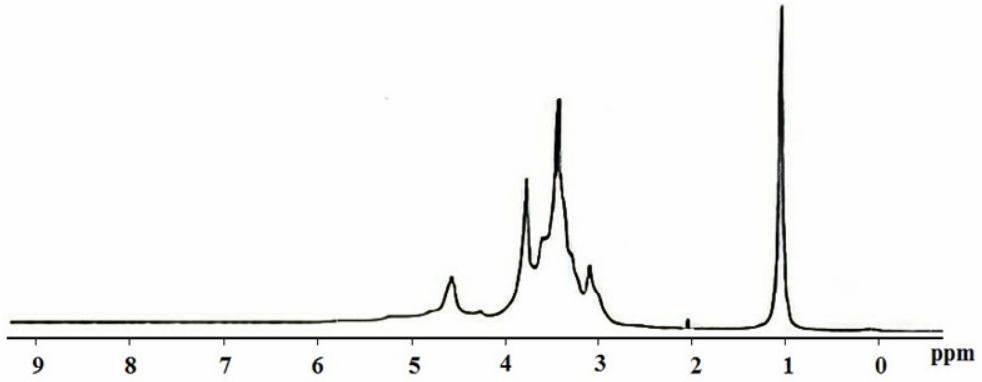

Figure 2: ${ }^{1} \mathrm{H}$ NMR spectrum for the $\mathrm{HPC}_{\mathrm{B}}$ sample prepared from dissolved bagasse pulp

\section{Thermal characterization}

Table 1 shows the DSC data (heating and cooling) for the $\mathrm{HPC}_{\mathrm{B}}$ prepared with DS 1.87 and that purchased from Aldrich $\left(\mathrm{HPC}_{\mathrm{P}}\right)$ with DS 3. Upon heating, both $\mathrm{HPC}_{\mathrm{B}}$ and $\mathrm{HPC}_{\mathrm{P}}$ become soft and then melt, leading to the formation of a mesophase at approximately at $145{ }^{\circ} \mathrm{C}$ and 130 ${ }^{\circ} \mathrm{C}$, and the corresponding enthalpy of these transitions are 51 and $82 \mathrm{~J} / \mathrm{g}$, respectively. The endothermic peaks detected at $220^{\circ} \mathrm{C}$ and $195{ }^{\circ} \mathrm{C}$ for $\mathrm{HPC}_{\mathrm{B}}$ and $\mathrm{HPC}_{\mathrm{P}}$, with the enthalpy of 7.6 and
$3.5 \mathrm{~J} / \mathrm{g}$, respectively, correspond to the transition from the thermotropic phase to the isotropic phase. The results of the investigations of phase transitions in HPC by means of DSC are consistent with the results presented in the literature. $^{25}$

When cooling, an endothermic effect is noted at $208{ }^{\circ} \mathrm{C}$ and $188{ }^{\circ} \mathrm{C}$ for $\mathrm{HPC}_{\mathrm{B}}$ and $\mathrm{HPC}_{\mathrm{P}}$, respectively, with enthalpy of 3.6 and $2.95 \mathrm{~J} / \mathrm{g}$, corresponding to the transition from the isotropic phase to the liquid crystalline phase. 
The thermograms for HPCs $\left(\mathrm{HPC}_{\mathrm{B}}\right.$ and $\left.\mathrm{HPC}_{\mathrm{P}}\right)$ reveal glass transition at $25{ }^{\circ} \mathrm{C}$ and $15{ }^{\circ} \mathrm{C}$, respectively. The $T_{g}$ decreases with the increasing hydroxypropoxy content ratio, i.e. introducing hydroxypropoxy groups may reduce the interactions of the unsubstituted hydroxyls of the cellulose chain as the polymer becomes much more amorphous, thus lowering the $\mathrm{T}_{\mathrm{g}}$. This explains the different behavior of the samples with different degrees of substitution: the HPC prepared with a lower number of hydroxypropoxy groups has higher $\mathrm{T}_{\mathrm{g}}$ and thermal stability than the purchased HPC (higher DS). ${ }^{25}$

\section{Liquid crystalline characteristics of $\mathrm{HPC}_{\mathrm{B}}$ prepared from dissolving bagasse pulp}

Hydroxypropyl cellulose is a semi-flexible cellulose derivative; it is both a thermotropic and lyotropic liquid crystalline polymer. ${ }^{26}$
Lyotropic and thermotropic LC-phase of $H P C_{B}$

PLM was used to characterize the liquid crystal phase of $\mathrm{HPC}_{\mathrm{B}}$. The birefringence was studied for the $\mathrm{HPC}_{\mathrm{B}}$ solutions $(40,50$, and 60 $\mathrm{wt} \%$ ) in DMA. Figure 3 shows the texture obtained from the $\mathrm{HPC}_{\mathrm{B}}$ solutions in DMA with 50 and $60 \mathrm{wt} \%$ concentrations. The solution shows strong birefringence and iridescent color. The picture taken for the 50 and $60 \mathrm{wt} \%$ solutions show birefringence. The $40 \mathrm{wt} \%$ solution did not show the liquid crystalline phase, since there was no indication of any birefringence. Hydroxypropyl cellulose was found to form a thermotropic liquid crystal phase between $145{ }^{\circ} \mathrm{C}$ and $220^{\circ} \mathrm{C}$.

Table 1

Thermal properties of HPCs

\begin{tabular}{lcccccc}
\hline HPCs & DS & $\mathrm{T}_{\mathrm{g}}{ }^{\circ} \mathrm{C}$ & $\mathrm{T}_{\mathrm{m}}{ }^{\circ} \mathrm{C}$ & $\Delta \mathrm{H}_{\mathrm{m}} \mathrm{J} / \mathrm{g}$ & $\mathrm{T}_{\mathrm{c}}{ }^{\circ} \mathrm{C}$ & $\Delta \mathrm{H}_{\mathrm{c}} \mathrm{J} / \mathrm{g}$ \\
\hline $\mathrm{HPC}_{\mathrm{B}}$ & 1.78 & 25 & 145 & 82 & 220 & 7.6 \\
$\mathrm{HPC}_{\mathrm{P}}$ & 3 & 15 & 130 & 51 & 195 & 3.5 \\
\hline
\end{tabular}

$\mathrm{T}_{\mathrm{g}}$ (glass transition temperature), $\mathrm{T}_{\mathrm{c}}$ (clearing temperature or isotropization temperature) and $\mathrm{T}_{\mathrm{m}}$ (softening temperature) of HPCs were determined from DSC
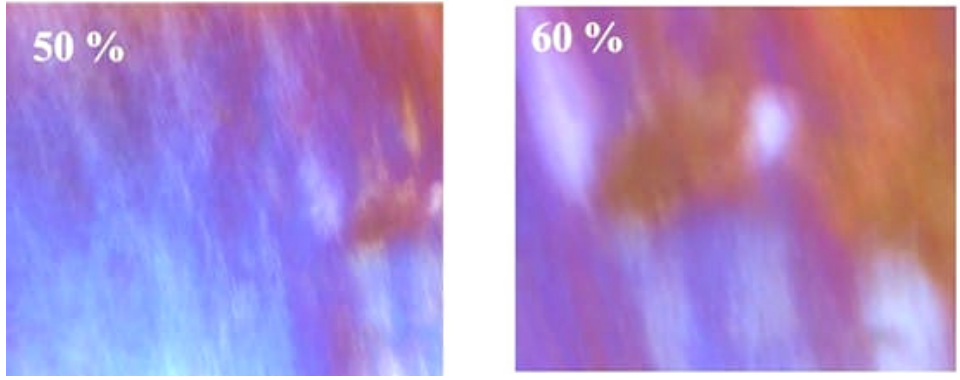

Figure 3: PLM images for the HPC solution in DMA (50 and $60 \mathrm{wt} \%$ ) at room temperature

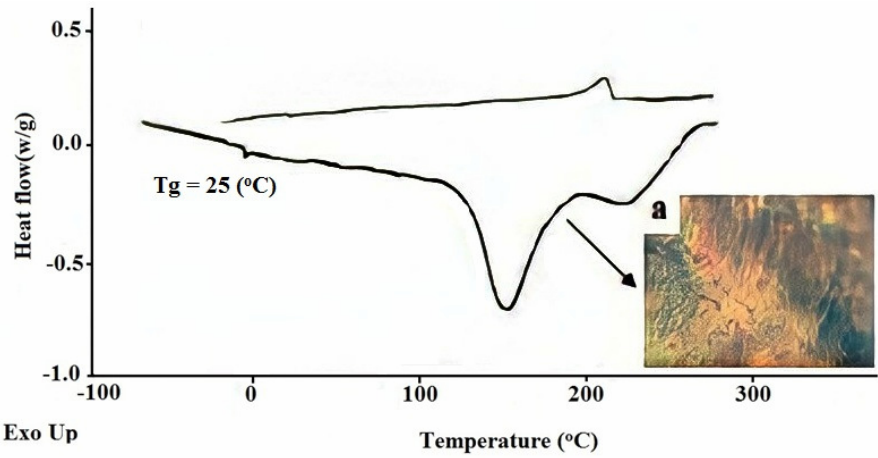

Figure 4: DSC heating/cooling curves of $\mathrm{HPC}_{\mathrm{B}}$, and PLM image of $\mathrm{HPC}_{\mathrm{B}}$ at $180{ }^{\circ} \mathrm{C}$ 
Figure 4 exhibits the DSC curve along with a PLM photomicrograph of $\mathrm{HPC}_{\mathrm{B}}$ at $180{ }^{\circ} \mathrm{C}$. $\mathrm{HPC}$ is semi-crystalline at room temperature and, upon heating, becomes soft and fluid, due to the formation of a mesophase, at approximately 145 ${ }^{\circ} \mathrm{C}$, and on further heating, the $\mathrm{HPC}_{\mathrm{B}}$ becomes isotropic at approximately $220{ }^{\circ} \mathrm{C}$. On cooling, a small endothermic peak at $208{ }^{\circ} \mathrm{C}(3.6 \mathrm{~J} / \mathrm{g})$ corresponds to the transition from the isotropic phase to the liquid crystalline phase.

The critical concentration (C.C.) was determined by measuring the refractive indices of the solutions in DMA. The critical concentration can be determined from the plot of the mean refractive index versus concentration (Fig. 4) and was found to be 48 , whereas it was 46 for the $\mathrm{HPC}_{\mathrm{P}}$

In a related study by Dong et al. ${ }^{27}$ an inverse relation between solubility and C.C. was reported, where the high solubility leads to the formation of the mesophase at low C.C., and relatively lower solubility leads to the formation of a mesophase at higher C.C. It is clear that the critical concentration for $\mathrm{HPC}_{\mathrm{B}}$ is lower than that of $\mathrm{HPC}_{\mathrm{P}}$. This is due to the good solubility of the purchased HPC with higher DS. The results implied that low critical concentration is needed for good solubility in the solvent.

\section{Derivatization of the synthesized $\mathrm{HPC}_{\mathrm{B}}$}

Some selected alkoxybenzoic acids bearing 2, 10 and 12 carbon atoms were used to prepare HPC derivatives and the new derivatives were denoted as ABPC- $m$, where $m$ refers to the number of carbon atoms. The derivatives were characterized by IR, 1H NMR spectroscopy, refractive index, DSC, and PLM. These compounds with a short terminal alkyl chain exhibit a nematic phase, and those with intermediate chain lengths show both a nematic and a smectic $\mathrm{C}$ phase; whereas the compounds with long alkyl chains show a smectic $\mathrm{C}$ phase only.

\section{FT-IR spectroscopy of $\mathrm{HPC}_{B}$ and its derivatives}

The infrared spectra for $\mathrm{HPC}_{\mathrm{B}}$ and modified HPC samples with alkoxybenzoic acids $(\mathrm{m}=2$, 10 and 12) are given in Figure 5. HPC shows a broad peak at around $3460 \mathrm{~cm}^{-1}$ assigned to the O$\mathrm{H}$ stretching vibration. The peak detected at around $2900 \mathrm{~cm}^{-1}$ is assigned to the $\mathrm{CH}$ asymmetric stretching vibration of the terminal methyl group.

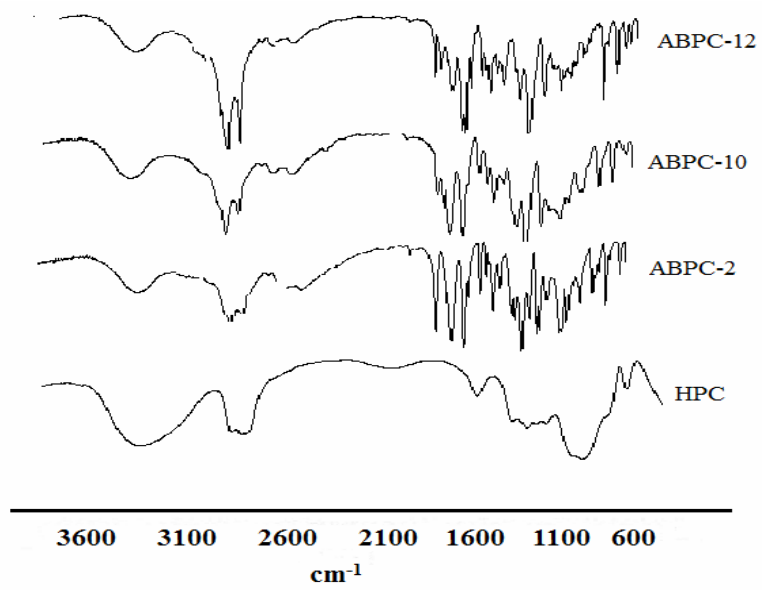

Figure 5: FTIR spectra for the synthesized HPC, ABPC-2, ABPC-10 and ABPC-12

The FTIR spectra of HPC and modified hydroxypropyl cellulose indicate the success of the esterification with the 4-alkoxybenzoic acid reagents, which is clearly confirmed by the appearance of new carbonyl ester bands around 1750,1760 and $1755 \mathrm{~cm}^{-1}$ stretching modes, for ABPC-2, ABPC-10 and ABPC-12, respectively. Also, the occurrence of new absorptions in the 
range of $650-800 \mathrm{~cm}^{-1}$, which were associated with the bending vibrations of the aromatic ring (Ar), confirms the esterification reaction. Moreover, the observed peaks at $1260 \mathrm{~cm}^{-1}, 1250$ $\mathrm{cm}^{-1}$ and $1255 \mathrm{~cm}^{-1}$ are assigned to $\mathrm{C}-\mathrm{O}-\mathrm{C}$ ester stretching vibrations of the ester group for ABPC2, ABPC-10 and ABPC-12, respectively.

\section{${ }^{1} \mathrm{H}$ NMR spectroscopy of the synthesized $\mathrm{HPC}_{B}$ and its derivatives}

The benzoylation of HPCB with 4alkoxybenzoic acids (ABPC- $m$ ), where $m=2,10$, and 12, was further confirmed with ${ }^{1} \mathrm{H}$ NMR. Figure 2 presents the ${ }^{1} \mathrm{H}$ NMR spectrum of the synthesized HPCB. The prepared HPC spectrum shows signals at $1.2 \mathrm{ppm}$ due to the methyl groups in the hydroxypropyl chain and at 2.8 to $4.5 \mathrm{ppm}$ corresponding to the cyclic glucose units, which are present in both HPCB and its derivatives. Upon derivatization of HPCB, the common signals at around 6.9 and $7.9 \mathrm{ppm}$ are due to aromatic protons. For ABPC-2, the resonance peak observed at $1.33 \mathrm{ppm}$ is attributed to the protons in terminal - $\mathrm{CH} 3$ in the alkoxy chain. The signal at $3.9 \mathrm{ppm}$ is assigned to the protons of $\mathrm{O}-\mathrm{CH}_{2}-\mathrm{CH}_{3}$. ABPC-10 and 12 showed similar absorptions around $0.95 \mathrm{ppm}$ for the terminal $-\mathrm{CH}_{3}$ groups and in the range of 1.1-1.8 ppm for the protons of $-\mathrm{CH}_{2}$ groups in the alkoxy chain.

\section{Phase behavior of ABPC-m}

The thermal transition temperatures (glass transition $\left(\mathrm{T}_{\mathrm{g}}\right)$, melting $\left(\mathrm{T}_{\mathrm{m}}\right)$, and clearing temperatures $\left.\left(\mathrm{T}_{\mathrm{c}}\right)\right)$ and their corresponding enthalpies $(\Delta \mathrm{H})$ are listed in Table 2.

Increasing the length of the side chain results in a decrease in the glass transition $\left(\mathrm{T}_{\mathrm{g}}\right)$, melting $\left(\mathrm{T}_{\mathrm{m}}\right)$, clearing temperatures $\left(\mathrm{T}_{\mathrm{c}}\right)$ and the corresponding enthalpies $(\Delta \mathrm{H})$. The temperature range between $T_{c}$ and $T_{g}$ of the LC phase becomes narrower with an increase in the side chain length. Based on all of the side-chain dependent thermal behaviors $\left(T_{g}, T_{c}\right.$, and $\left.T_{c}-T_{g}\right)$, it is clearly predicted that not only the backbone, but also the side chains are involved in the formation of the LC phases and phase transitions. Extending the chain and moving the branch away from the core dilutes the effect of the branch, but LC phase stabilities are still very low when compared to the unbranched analogue, which in fact has a much lower melting point. ${ }^{22}$

From Table 2, it is clear that sample ABPC-2 did not show any thermotropic mesophase. Nevertheless, it still exhibited lyotropic LC. On the other hand, samples ABPC-10 and 12 showed both lyotropic and thermotropic liquid crystal behavior, as detected by both DSC and PLM.

Table 2

Thermal properties of ABPC- $m$

\begin{tabular}{lcccccccccc}
\hline ABPC- $m$ & $\begin{array}{c}\mathrm{Tm} \\
\left({ }^{\circ} \mathrm{C}\right)\end{array}$ & $\begin{array}{c}\Delta \mathrm{Hm} \\
(\mathrm{J} / \mathrm{g})\end{array}$ & $\begin{array}{c}\mathrm{Tg} \\
\left({ }^{\circ} \mathrm{C}\right)\end{array}$ & $\begin{array}{c}\Delta \mathrm{Hg} \\
(\mathrm{J} / \mathrm{g})\end{array}$ & $\mathrm{DS}$ & $\begin{array}{c}\mathrm{Tc} \\
\left({ }^{\circ} \mathrm{C}\right)\end{array}$ & $\begin{array}{c}\Delta \mathrm{Hc} \\
(\mathrm{J} / \mathrm{g})\end{array}$ & $\begin{array}{c}\Delta \mathrm{T}\left({ }^{\circ} \mathrm{C}\right) \\
\mathrm{Tc}-\mathrm{T}_{\mathrm{g}}\end{array}$ & $\begin{array}{c}\Delta \mathrm{T}\left({ }^{\circ} \mathrm{C}\right) \\
\mathrm{Tc}-\mathrm{Tm}\end{array}$ & $\begin{array}{c}\Delta \mathrm{T}\left({ }^{\circ} \mathrm{C}\right) \\
\mathrm{Tm}-\mathrm{T}_{\mathrm{g}}\end{array}$ \\
\hline HPC $*$ & 145 & 162.6 & 25 & 2.8 & 1.87 & 220 & 3.2 & 195 & 45 & 120 \\
ABPC-2 & 190 & 166.7 & -5 & 3.4 & 2.1 & - & - & - & - & 185 \\
ABPC-10 & 95 & 115.3 & -50.6 & 2.5 & 1.77 & 150 & 7.6 & 99.4 & 55 & 45 \\
ABPC-12 & 75 & 92 & -62 & 1.67 & 1.62 & 110 & 4.5 & 48 & 35 & 13 \\
\hline
\end{tabular}

$*$ HPC prepared from dissolving bagasse pulp

Table 3

Optical properties of ABPC- $m$

\begin{tabular}{lccccc}
\hline ABPC- $m$ & $n_{e}$ & $n_{o}$ & $\begin{array}{c}\text { Birefringence, } \\
\Delta n \times 10^{3}\end{array}$ & $n$ & $\begin{array}{c}\text { Critical conc. } \\
(\text { wt } \%)\end{array}$ \\
\hline Prepared HPC & 1.4555 & 1.4508 & 4.7 & 1.4523 & 48 \\
ABPC-2 & 1.4695 & 1.4641 & 5.4 & 1.4659 & 47 \\
ABPC-10 & 1.4581 & 1.4537 & 4.4 & 1.4551 & 45 \\
ABPC-12 & 1.4671 & 1.4648 & 2.3 & 1.4655 & 45 \\
\hline
\end{tabular}

From Table 2, it is clear that sample ABPC-2 did not show any thermotropic mesophase. Nevertheless, it still exhibited lyotropic LC. On the other hand, samples ABPC-10 and 12 showed both lyotropic and thermotropic liquid crystal behavior, as detected by both DSC and PLM. 


\section{Determination of critical concentration}

The critical concentration can be estimated by refractive index $(n)$ measurements of the series of HPC and ABPC- $m$ solutions in DMA with various concentrations (40, 50 and $60 \mathrm{wt} \%)$. An Abbe refractometer was used for measuring the two principal refractive indices $n_{e}$ (extraordinary) and $n_{o}$ (ordinary) at $25{ }^{\circ} \mathrm{C}$. Figure 4 shows the plot of the mean refractive index versus the concentration of ABPC- $m$.
Table 3 presents the extraordinary refractive index $\left(n_{e}\right)$, ordinary refractive index $\left(n_{o}\right)$, birefringence $\left(\Delta n=n_{e}-n_{o}\right)$, average refractive index $(n)$, and the critical concentration for the ABPC- $m$ samples. It is clear from the table that, upon increasing the length of the alkoxy groups, the birefringence $(\Delta n)$ of ABPC- $m$ decreases and the average refractive index did not vary regularly with the chain length $(m)$.
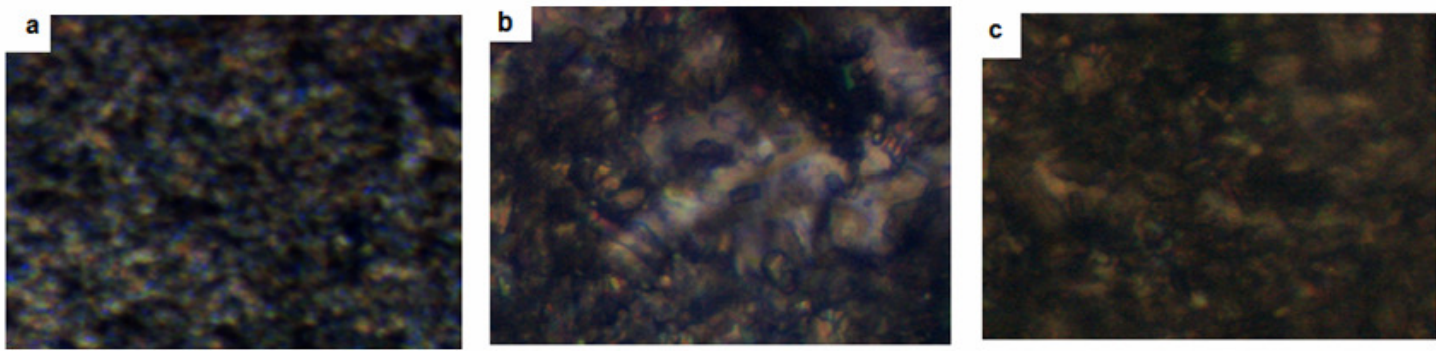

Figure 6: PLM images of a) ABPC-2, b) ABPC-10 and c) ABPC-12 in 60 wt\% DMA at room temperature
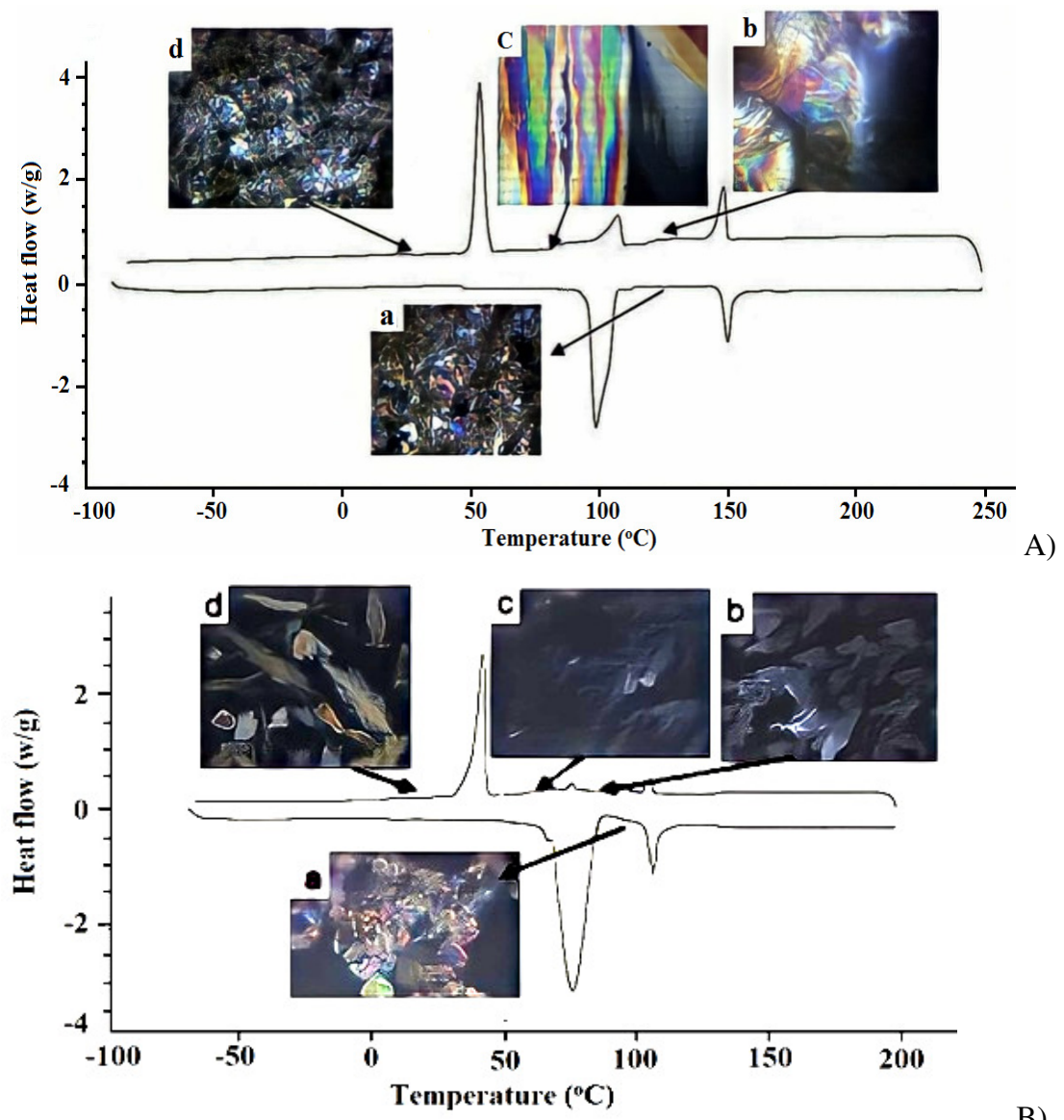

A)

B)

Figure 7: DSC thermograms and observed PLM images for (A) ABPC-10, a) upon heating to $125.0^{\circ} \mathrm{C}$, and cooling to b) $120.0^{\circ} \mathrm{C}$, c) $75.0^{\circ} \mathrm{C}$, and d) $40^{\circ} \mathrm{C}$; and (B) ABPC-12, a) upon heating to $100.0^{\circ} \mathrm{C}$, and cooling to b) $95.0^{\circ} \mathrm{C}$, c) $70.0{ }^{\circ} \mathrm{C}$, and d) $40{ }^{\circ} \mathrm{C}$ 
The derivatization with alkoxybenzoic acids furnishes easily soluble samples in common organic solvents. This solubility could be ascribed to the rigidity and unfolding of the macromolecular chains due to the steric hindrance of the substituted long chains. These new characteristics led to easy formation of the liquid crystal. $^{28}$

Below the critical concentration of ABPC- $m$ in DMA solution, the isotropic feature at room temperature was shown and this result was also confirmed by PLM; where the non-continuous mesophase was formed. At concentrations higher than the critical one, the mesophase becomes continuous and colored. Figure 6 shows the birefringence texture of the derivatives' solutions of $60 \%$ concentrations.

\section{Liquid crystal phase transformation}

Figure 7 (A) illustrates the DSC heating and cooling cycles for sample ABPC-12 and its corresponding morphologies upon heating and cooling. The endothermic peak at $95{ }^{\circ} \mathrm{C}$ is attributed to the change of the crystal structure from the crystalline to the nematic phase. The enthalpy calculated from this peak was $58.5 \mathrm{~J} / \mathrm{g}^{-1}$. On further heating up to $150{ }^{\circ} \mathrm{C}$, the nematic phase lost its birefringence and was transformed to an isotropic phase.

On cooling, it can be seen that the nematic phase (image b) grew from isotropic at $149{ }^{\circ} \mathrm{C}$, the endothermic peak at $149{ }^{\circ} \mathrm{C}$, and possessing $\Delta \mathrm{H} 6.4 \mathrm{~J} / \mathrm{g}^{-1}$. When the temperature decreased to $110{ }^{\circ} \mathrm{C}$, the mesophase changed to the smectic phase (image c). The corresponding enthalpy was found to be $4.2 \mathrm{~J} / \mathrm{g}^{-1}$. The change to the crystalline phase upon cooling was found to occur at $40{ }^{\circ} \mathrm{C}$.

Figure 7 (B) presents the DSC curve and the corresponding morphologies for ABPC-12 during heating and cooling. On heating, it could be seen that ABPC-12 showed a nematic mesophase between $75{ }^{\circ} \mathrm{C}$ and $110{ }^{\circ} \mathrm{C}$ (image a). By increasing the temperature to $75{ }^{\circ} \mathrm{C}$, an endothermic peak with enthalpy of $92 \mathrm{~J} / \mathrm{g}$ was noted; the nematic phase was observed before the molecule became disordered and converted to isotropic liquid at $110{ }^{\circ} \mathrm{C}$, having $\Delta \mathrm{H}=2.1 \mathrm{~J} / \mathrm{g}$.

On cooling, the isotropic phase to nematic transition was observed at $109.5^{\circ} \mathrm{C}$, which was only $0.5{ }^{\circ} \mathrm{C}$ lower than the clearing temperature measured on heating, with $\Delta \mathrm{H}=2 \mathrm{~J} / \mathrm{g}$ (image b). The nematic structure appeared at $109.5^{\circ} \mathrm{C}$ and when the temperature was decreased to $78{ }^{\circ} \mathrm{C}$.
The nematic structure changed to the smectic phase with cooling until $78{ }^{\circ} \mathrm{C}$, with enthalpy of $4.2 \mathrm{~J} / \mathrm{g}$ (image c).

The more ordered crystallization structure (image d) formed at $50.0{ }^{\circ} \mathrm{C}$. In comparison with the heating process, the crystallization temperature decreased by about $25^{\circ} \mathrm{C}$ on cooling, whereas the corresponding enthalpy was $\Delta \mathrm{H}=$ $55.6 \mathrm{~J} / \mathrm{g}$ (the enthalpy decreased by about $37 \mathrm{~J} / \mathrm{g}$ ).

\section{CONCLUSION}

Derivatization of $\mathrm{HPC}_{\mathrm{B}}$ prepared from dissolved bagasse pulp was carried out and it was observed that the glass transition $\left(\mathrm{T}_{\mathrm{g}}\right)$ and clearing temperature $\left(T_{c}\right)$ have the same trend when increasing the length of the alkoxy chain. The behavior of ABPC- $m$ revealed that both the backbone of cellulose and the length of the alkoxy chain of the acid have affected the formation of the liquid crystalline phase. A series of 4alkyoxybenzoyloxypropyl cellulose (ABPC-m) samples were synthesized via the esterification of the synthesized hydroxypropyl cellulose (HPC) with 4-alkoxybenzoic acid, bearing different numbers of carbon atoms. The molecular structure of the ABPC- $m$ was confirmed by Fourier transform infrared (FT-IR) spectroscopy and ${ }^{1} \mathrm{H}$ NMR spectroscopy. The liquid crystalline (LC) phases and transition behaviors were investigated using differential scanning calorimetry (DSC), polarized light microscopy (PLM), and refractometry. It was found that the glass transition $\left(\mathrm{T}_{\mathrm{g}}\right)$ and clearing $\left(\mathrm{T}_{\mathrm{c}}\right)$ temperatures decreased when increasing the length of the alkoxy chain. It was observed that the derivatives with an odd number of carbon atoms were nonmesomorphic. This series of ABPC- $m$ polymers exhibited characteristic features of cholesteric LC phases between their glass transition and isotropization temperatures.

\section{REFERENCES}

1 H. Awada, P. H. Elchinger, P. A. Faugeras, C. Zerrouki, D. Montplaisir et al., BioResources, 10, 2044 (2015), https://bioresources.cnr.ncsu.edu/wp-content content/uploads/2016/06/BioRes_10_2_2044_Awada_ EFZMBZ_Chem_Mod_Kraft_Cellulose_Fibres_6511. pdf

Z. N. T. Mzimela, L. Z. Linganiso, N. Revaprasadu and T. E. Motaung, Mater. Res., 21, (2018), http://dx.doi.org/10.1590/1980-5373-mr-2017-0750

3 N. Phinichka, and S. Kaenthong, J. Mater. Res. Technol., $\quad 7, \quad 55 \quad$ (2018), https://doi.org/10.1016/j.jmrt.2017.04.003 
4 J. P. Reddy and J. W. Rhim, J. Nat. Fibers, 15, 465 (2018), https://doi.org/10.1080/15440478.2014.945227

J. Goldemberg, Biotechnology for Biofuels, 1, 6 (2008), https://doi.org/10.1186/1754-6834-1-6

6 T. Barroso, M. Temtem, A. Hussain, A. AguiarRicardo and A. C. Roque, J. Membrane Sci., 348, 224 (2010), https://doi.org/10.1016/j.memsci.2009.11.004

7 U. P. Rodrigues-Filho, Y. Gushikem, M. D. C. Gonçalves, R. C. Cachichi and S. C. de Castro, Chem. Mater., $\quad 8, \quad 1375 \quad$ (1996), https://doi.org/10.1021/cm950528g

8 R. G. Viera, G. Rodrigues Filho, R. M. de Assunção, C. D. S. Meireles, J. G. Vieira et al., Carbohyd. Polym., 67, 182 (2007), https://doi.org 10.1016/j.carbpol.2006.05.007

9 T. E. Motaung and M. J. Mochane, J. Thermoplast. Compos. Mater., 31, $1416 \quad$ (2018), https://doi.org/10.1177/0892705717738292

10 L. Golbaghi, M. Khamforoush and T. Hatami, Carbohyd. Polym., 174, $780 \quad$ (2017), https://doi.org/10.1016/j.carbpol.2017.06.123

11 Y. Ge and Z. Li, J. Macromol. Sci., A, 50, 757 (2013), https://doi.org/10.1080/10601325.2013.792646

12 K. Hayata, T. Suzuki, M. Fukawa and S. Furumi, J. Photopolym. Sci. Technol., 32, 645 (2019), https://doi.org/10.2494/photopolymer.32.645

13 H. Ishii, K. Sugimura and Y. Nishio, Cellulose, 26, 399 (2019), https://doi.org/10.1007/s10570-018-21766

14 R. S. Werbowyj and D. G. Gray, Mol. Cryst. Liq. Cryst., $\quad 34, \quad 97 \quad$ (1976),

https://doi.org/10.1080/15421407608083894

15 K. Shimamura, J. L. White and J. F. Fellers, J. Appl. Polym. Sci., 26, $2165 \quad$ (1981), https://doi.org/10.1002/app.1981.070260705

16 D. G. Gray, J. Appl. Polym. Sci.: Appl. Polym. Symp., $\quad 37, \quad 179 \quad$ (1983), https://www.osti.gov/biblio/6980365

17 T. Yamagishi, T. Fukuda, T. Miyamoto and J. Watanabe, Polym. Bull., 20, 373 (1988), https://doi.org/10.1007/BF00255739

18 T. Yamagishi, T. Fukuda, T. Miyamoto and J. Watanabe, Mol. Cryst. Liq. Cryst., 172, 17 (1989), https://doi.org/10.1080/00268948908042147

19 T. Yamagishi, T. Fukuda, T. Miyamoto, Y. Takashina, Y. Yakoh et al., Liq. Cryst., 10, 467 (1991), https://doi.org/10.1080/02678299108036436
20 P. S. N. Bhadania, S. L. Tseng and D. G. Gray, Makromol. Chem., 184, $1727 \quad$ (1983), https://doi.org/10.1002/macp.1983.021840816

21 M. H. Godinho, P. L. Almeida and J. L. Figueirinhas, Materials, 7, $4601 \quad$ (2014), https://doi.org/10.3390/ma7064601

22 N. A. El-Wakil, Y. Fahmy, R. E. M. Abou-Zeid, A. Dufresne and S. El-Sherbiny, Bioresources, 5, 1834 (2010), https://doi.org/10.15376/biores.5.3.1834-1845

23 R. C. Sun, J. M. Fang, J. Tomkinson, Z. C. Geng and J. C. Liu, Carbohyd. Polym., 44, 29 (2001), https://doi.org/10.1016/S0144-8617(00)00196-X

24 D. Klemm, B. Philpp, T. Heinze, U. Heinze and W. Wagenknecht, "Comprehensive Cellulose Chemistry. Volume 1: Fundamentals and Analytical Methods", Wiley-VCH Verlag GmbH, 1998

25 M. Larsson, A. Larsson and M. Stading, Annual Transactions of the Nordic Rheology Society, 18, 59 (2010),

http://publications.lib.chalmers.se/records/fulltext/1266 56/local_126656.pdf

26 P. Zugenmaire, in "Handbook of Liquid Crystals", edited by D. Demus, J. Goodby, G. W. Gray, 1998, p. 3-453, https://doi.org/10.1002/9783527620593.ch9

27 D. Yanming and Z. Shiying, Chin. J. Polym. Sci., 14, 134 (1996),

http://www.cjps.org/article/id/660d6a2d-f1f7-47ae8851-67d857460f6a?pageType=en

28 C. Wang, Y. Dong and H. Tan, Carbohyd. Res., 338, 535 (2003), https://doi.org/10.1016/s00086215(02)00496-2 